\title{
Comunicação
}

\section{Desempenho de genótipos de feijão-mungo-verde semeados no inverno na Zona da Mata de Minas Gerais}

\author{
Rogério Faria Vieira ${ }^{1}$, Trazilbo José de Paula Júniorl, Luciano Luís Jacob², Miller da Silva Lehner², \\ Josiane dos Santos ${ }^{2}$
}

\section{RESUMO}

Avaliou-se o desempenho do feijão-mungo-verde, semeado no inverno, na Zona da Mata de Minas Gerais, a 400 (Oratórios) e 720 m (Coimbra) de altitude. Dez genótipos foram semeados no final de julho, ou no início de agosto, no delineamento em blocos ao acaso, com quatro repetições. Irrigações por aspersão complementaram as chuvas. A primeira vagem amadureceu aos 73,3 (Oratórios) e aos 79,9 dias após a emergência (DAE) (Coimbra). A altura das plantas foi maior em Oratórios $(62,4 \mathrm{~cm})$ do que em Coimbra $(37,1 \mathrm{~cm})$. Em Coimbra, doenças causadas por Erysiphe polygoni e Ascochita sp. foram moderadas. Em Oratórios, foram feitas três colheitas entre 81 e 94 DAE; em Coimbra, duas: 88 e 100 DAE. As produtividades médias foram de 1093 (Oratórios) e 801 kg/ha (Coimbra). As sementes colhidas em Oratórios apresentaram aspecto ótimo ou bom; em Coimbra, bom ou regular. Concluímos que o plantio do feijãomungo-verde no inverno, em altitudes entre 400 e $720 \mathrm{~m}$, proporciona produtividades relativamente modestas, especialmente a $720 \mathrm{~m}$, onde as condições climáticas favorecem algumas doenças.

Palavras-chave: Vigna radiata L., qualidade de semente, ciclo de vida.

\section{ABSTRACT}

\section{Mungbean genotypes sown in winter in the Zona da Mata of Minas Gerais}

The objective of this study was to evaluate mungbean performance sown during winter in the Zona da Mata region of Minas Gerais, Brazil, at altitudes of 400 (Oratórios) and $720 \mathrm{~m}$ (Coimbra). Ten genotypes were sown at the end of July or at the beginning of August in a completely randomized block design with four replicates. Sprinkler irrigations complemented the rainfalls. The first mature pod appeared at 73.3 (Oratórios) and 79.9 days after emergence (DAE) (Coimbra). Plant heights $(62.4 \mathrm{~cm})$ were greater in Oratórios than in Coimbra $(37.1 \mathrm{~cm})$. The diseases powdery mildew (Erisyphe polygoni) and ascochyta blight (Ascochyta sp.) were moderate in Coimbra. Three harvests were carried out in Oratórios, between 81 and 94 DAE, and between 88 and 100 DAE in Coimbra. Average yields were 1093 (Oratórios) and $801 \mathrm{~kg} / \mathrm{ha}$ (Coimbra). Seeds harvested in Oratórios had very good or good aspect; in Coimbra, they were good or regular. It was conclude that mungbean yield is modest when sown in winter, especially at $720 \mathrm{~m}$, where climate conditions favor some diseases.

Key words: Life cycle, seed quality, Vigna radiata L., yield.

Recebido para publicação em agosto de 2008 e aprovado em março de 2011

1Engenheiros-Agrônomos, Doutores. Empresa de Pesquisa Agropecuária de Minas Gerais, Cx. P. 216, 36570-000, Viçosa, MG, Brasil. rfvieira@epamig.br; trazilbo@epamig.br ${ }^{2}$ Engenheiros-Agrônomos. Empresa de Pesquisa Agropecuária de Minas Gerais, Cx. P. 216, 36570-000, Viçosa, MG, Brasil. luciano.jacob@epamig.br; josesantos22@bol.com.br; millerlehner@gmail.com

Rev. Ceres, Viçosa, v. 58, n.3, p. 402-405, mai/jun, 2011 


\section{INTRODUÇÃO}

O feijão-mungo-verde (Vigna radiata (L.) Wilczek) é uma leguminosa granífera nativa da Ásia, onde é cultivada em grandes extensões. No Brasil, sua produção é incipiente, mas, com o aumento da produção e consumo do broto de feijão (moyashi), o interesse por ela vem aumentando. As exigências dos produtores de broto de feijão, por ocasião da aquisição de sementes, é que tenham alta germinação e vigor e estejam isentas de fungos e bactérias, fatores determinantes na produção de brotos de qualidade.

A temperatura mínima média para o desenvolvimento dessa espécie é de 20 a $22{ }^{\circ} \mathrm{C}$ e, a ótima, de 28 a $30{ }^{\circ} \mathrm{C}$, talvez um pouco acima, se as chuvas forem adequadas. A maturação das vagens é desuniforme; a primeira amadurece entre 46 e 70 dias após o plantio, dependendo do genótipo e, especialmente, das condições climáticas (Vieira et al., 2001).

O mungo-verde produz ao redor de $2000 \mathrm{~kg} / \mathrm{ha}$ quando semeado na primavera-verão (Vieira et al., 2003; Vieira et al., 2005). A maior produtividade alcançada no Brasil deu-se com o plantio em janeiro, em Prudente de Morais, MG, onde o cultivar MGS Esmeralda rendeu 2550 kg/ha. Na Zona da Mata de Minas Gerais, em razão do risco de coincidir a maturação das plantas com período chuvoso, não se recomenda o seu plantio na primavera até meados do verão (Vieira et al., 2001). Logo, o período mais favorável para o plantio dessa espécie é fevereiro, podendo se estender, em locais de inverno pouco rigoroso, até o final de março. Outra possível época de plantio na Zona da Mata é o inverno, mais especificamente no final de julho ou no início de agosto, quando a temperatura começa a se elevar.

O objetivo foi avaliar o desempenho do feijão-mungoverde, semeado no inverno, em altitudes entre 400 e 720 m, na Zona da Mata de Minas Gerais.

\section{MATERIAL E MÉTODOS}

$\mathrm{O}$ estudo foi conduzido em gleba pertencente à Universidade Federal de Viçosa, em Coimbra, e na fazenda experimental da Empresa de Pesquisa Agropecuária de Minas Gerais, em Oratórios, ambas localizadas na Zona da Mata de Minas Gerais. Coimbra está a $720 \mathrm{~m}$ de altitude, na latitude de $20^{\circ} 51^{\prime} \mathrm{S}$ e longitude de $42^{\circ} 46^{\prime} \mathrm{O}$. Oratórios está a $400 \mathrm{~m}$ de altitude, na latitude de $20^{\circ} 24^{\prime} \mathrm{S}$ e longitude de $42^{\circ} 48^{\prime} \mathrm{O}$.

Foram avaliados 10 genótipos selecionados de ensaios conduzidos anteriormente (Vieira et al., 2005). Com exceção do Tifton (Tabela 1), obtido na Geórgia, EUA, os demais se originaram do "Asian Vegetable Research and Development Center" (AVRDC), localizado em Formosa. O cultivar Ouro Verde MG-2 foi lançado em 2000
(Vieira et al., 2002) e o 'MGS Esmeralda', em 2008 (Vieira et al., 2008).

Em Coimbra, a semeadura foi feita em 7 de agosto de 2002; em Oratórios, em 24 de julho de 2002. Na adubação de plantio, foram empregados $700 \mathrm{~kg} / \mathrm{ha}$ do formulado 414-8 (N- $\left.\mathrm{P}_{2} \mathrm{O}_{5}-\mathrm{K}_{2} \mathrm{O}\right)$ e, em cobertura, aos 20 dias após a emergência (DAE) das plântulas, $250 \mathrm{~kg} / \mathrm{ha}$ de sulfato de amônio. O controle de plantas daninhas foi realizado com a mistura dos herbicidas fomesafen $(0,25 \mathrm{~kg} / \mathrm{ha})$ e fluazifopp-butil $(0,20 \mathrm{~kg} / \mathrm{ha})$, mais capinas manuais. Pragas, especialmente cigarrinha-verde (Empoasca kraemeri) e vaguinha (Cerotoma sp.), foram combatidas com o inseticida monocrotophos $(0,3 \mathrm{~L} / \mathrm{ha})$. Não foi feito controle de doenças. Os ensaios foram irrigados semanalmente, por aspersão, com lâmina de água de aproximadamente $50 \mathrm{~mm}$.

Empregou-se o delineamento em blocos ao acaso, com quatro repetições. As parcelas tinham duas fileiras de $5 \mathrm{~m}$ de comprimento, espaçadas de $0,5 \mathrm{~m}$. Uma fileira do 'Ouro Verde MG 2' serviu de bordadura externa. Foram usadas 20 sementes por metro. Na colheita, eliminou-se $0,5 \mathrm{~m}$ de cada extremidade da parcela.

Foram feitas as seguintes determinações ou anotações: emergência, início do florescimento, aparecimento da primeira vagem madura, altura de plantas, intensidade de doenças, produtividade, percentagem da produção total obtida em cada colheita, aspecto comercial das sementes e massa de 100 sementes. A emergência foi anotada quando $90 \%$ das plântulas emergentes estavam em posição vertical; o início da floração, quando $50 \%$ das plantas tinham pelo menos uma flor aberta (dado obtido apenas em Oratórios); o aparecimento da primeira vagem madura, quando $50 \%$ das plantas apresentavam pelo menos uma vagem seca. A altura foi avaliada em 10 plantas, escolhidas ao acaso, em início de maturação. A intensidade de doenças foi avaliada com base na escala de avaliação de 1 a 9, adaptada de Van Shoonhoven e Pastor Corrales (1987): 1,1 a 2,5 (leve); 2,6 a 4,1 (leve/moderada); 4,2 a 5,7 (moderada); 5,8 a 7,3 (moderada/severa); e maior que 7,4 (severa). A produtividade e a massa de 100 sementes foram estimadas com sementes com $11 \%$ de água. $\mathrm{O}$ aspecto comercial das sementes foi avaliado visualmente, após cada colheita, levando-se em conta mancha e descoloração no tegumento, com base nesta escala arbitrária: 1 ótimo, 2 - bom, 3 - regular, 4 -ruim e 5 - péssimo.

Os dados foram submetidos à análise de variância, e as médias foram comparadas pelo teste de Tukey, a 5\% de probabilidade.

\section{RESULTADOS E DISCUSSÃO}

Em ambos os locais, a emergência ocorreu 11 dias após a semeadura. Em período mais quente, a emergência ocorre com sete dias (Vieira et al., 2003). Em Oratórios, a 
floração ocorreu entre 46,5 e 51,7 DAE (Tabela 1), tempo entre 13,5 e 18,6 dias mais longo em relação a dezembro e março (Vieira et al., 2003; Vieira et al., 2005). Como em Coimbra as temperaturas são mais baixas do que em Oratórios, e o tempo para o aparecimento da primeira vagem madura foi mais longo em Coimbra (Tabelas 1 e 2), infere-se que a floração neste último local deve ter começado com mais de $50 \mathrm{DAE}$. Em Oratórios, a primeira vagem madura surgiu entre 71,5 e 76,2 DAE (Tabela 1). Esse tempo foi mais longo que o verificado em plantio em março, em Viçosa (Vieira et al., 2005), e entre 16,8 e 20,2 dias mais longo em relação a dezembro ou janeiro (Vieira et al., 2003; Vieira et al., 2005).

Em média, a altura das plantas em Coimbra $(31,7 \mathrm{~cm})$ (Tabela 2) foi a metade em relação a Oratórios $(62,4 \mathrm{~cm})$ (Tabela 1). Esta última altura média ficou dentro da faixa verificada em ensaios conduzidos entre janeiro e março na Zona da Mata (Vieira et al., 2005).

Em Coimbra, o míldio-pulverulento (Erysiphe polygoni DC) ocorreu de forma leve/moderada a moderada e, a ascoquitose (Ascochyta sp.), de leve a leve /moderada. Ambas as doenças são favorecidas pelo clima ameno do final de inverno (Tabela 3). O clima relativamente seco de agosto a outubro (Tabela 3) é favorável ao míldiopulverulento (Vieira et al., 2001). Os genótipos VC 4080A e Tifton estiveram entre os mais resistentes ao míldiopulverulento e à ascoquitose, respectivamente. Em Oratórios, o míldio-pulverulento foi observado de forma leve nas plantas.

Em Oratórios, a primeira colheita foi feita aos $81 \mathrm{DAE}$ ( 25 de outubro), obtendo-se $55,1 \%$ da produção total; duas outras colheitas foram realizadas aos $87(39,9 \%$ do total) e aos 94 DAE. Em Coimbra, a primeira colheita foi feita aos 88 DAE (14 de novembro), com $71 \%$ da produção total; uma segunda colheita foi realizada aos $100 \mathrm{DAE}$. Esses ciclos de vida são bem mais longos em relação aos plantios em dezembro ou janeiro, época em que a colheita pode ser feita até $67 \mathrm{DAE}$ (Vieira et al., 2005). Em relação ao plantio em fevereiro ou março (Vieira et al., 2005), entretanto, a diferença encurta para uma (Oratórios) a duas semanas (Coimbra).

Não houve diferença significativa entre as produtividades dos genótipos em ambas as localidades. Em média, ela foi mais alta em Oratórios (1093 kg/ha) do que em Coimbra (801 kg/ha) (Tabelas 1 e 2). Na Zona da Mata, o plantio do mungo-verde nos meses mais quentes do ano, entre novembro e fevereiro, proporciona rendimentos em torno de $2000 \mathrm{~kg} / \mathrm{ha}$ (Vieira et al., 2003; Vieira et al., 2005).

$\mathrm{O}$ aspecto comercial das sementes (primeira colheita) foi melhor em Oratórios (entre ótimo e bom) do que em Coimbra (bom) (Tabelas 1 e 2). Na segunda colheita, o aspecto comercial manteve-se entre ótimo e bom em Oratórios, mas caiu para entre bom e regular em Coimbra (dados não apresentados). Em Coimbra, em decorrência das baixas temperaturas de julho, a semeadura foi feita em 7 de agosto. Esse retardamento da semeadura, em relação a Oratórios, e o mais longo ciclo de vida dos genótipos no clima mais frio (Tabela 3 ) resultaram em colheitas em novembro, quando choveu mais do que em outubro (Tabela 3). A massa média das sementes colhidas em Oratórios foi semelhante à das colhidas em Coimbra e variou pouco, em relação à de ensaios conduzidos em meses mais quentes (Duque \& Pessanha, 1990; Vieira et al.,2005).

Tabela 1. Comparação entre genótipos de feijão-mungo-verde semeados no inverno em Oratórios, MG

\begin{tabular}{lccccccc}
\hline Genótipos & $\begin{array}{c}\text { Emergência } \\
\text { ao início da } \\
\text { floração } \\
\text { (dias) }\end{array}$ & $\begin{array}{c}\text { Emergência } \\
\text { à primeira } \\
\text { vagem } \\
\text { madura (dias) }\end{array}$ & $\begin{array}{c}\text { Altura } \\
\text { de planta } \\
(\mathbf{c m})\end{array}$ & $\begin{array}{c}\text { Primeira } \\
\text { colheita } \\
(\% \text { do total) }\end{array}$ & $\begin{array}{c}\text { Produtividade } \\
\left(\mathbf{k g ~ h a}^{-1}\right)\end{array}$ & $\begin{array}{c}\text { Aspecto } \\
\text { comercial das }^{\text {sementes }}\end{array}$ & $\begin{array}{c}\text { Massa de 100 } \\
\text { sementes } \\
\text { (g) }\end{array}$ \\
\hline O. Verde MG-2 & $49,5 \mathrm{ab}^{1}$ & $76,2 \mathrm{a}$ & $68,2 \mathrm{a}$ & $37,9 \mathrm{~d}$ & $1036^{\mathrm{ns}}$ & $1,75 \mathrm{a}$ & $5,0 \mathrm{~cd}$ \\
VC 4080A & $48,5 \mathrm{ab}$ & $73,0 \mathrm{bcd}$ & $58,7 \mathrm{~b}$ & $58,8 \mathrm{abc}$ & 1084 & $1,57 \mathrm{ab}$ & $6,9 \mathrm{ab}$ \\
VC 6148-B-16 & $49,5 \mathrm{ab}$ & $74,7 \mathrm{abc}$ & $60,5 \mathrm{~b}$ & $46,8 \mathrm{bcd}$ & 950 & $1,55 \mathrm{ab}$ & $7,8 \mathrm{a}$ \\
V 3476 & $47,0 \mathrm{~b}$ & $71,5 \mathrm{~d}$ & $60,9 \mathrm{~b}$ & $66,7 \mathrm{a}$ & 1083 & $1,42 \mathrm{ab}$ & $4,8 \mathrm{~cd}$ \\
VC 1973A & $46,5 \mathrm{~b}$ & $72,5 \mathrm{~cd}$ & $72,2 \mathrm{a}$ & $64,9 \mathrm{ab}$ & 1170 & $1,67 \mathrm{ab}$ & $6,3 \mathrm{abcd}$ \\
MGS Esmeralda & $47,5 \mathrm{~b}$ & $73,0 \mathrm{bcd}$ & $60,8 \mathrm{~b}$ & $58,0 \mathrm{abc}$ & 1100 & $1,35 \mathrm{~b}$ & $6,1 \mathrm{bcd}$ \\
Tifton & $51,7 \mathrm{a}$ & $75,5 \mathrm{ab}$ & $71,5 \mathrm{a}$ & $39,4 \mathrm{~cd}$ & 1084 & $1,52 \mathrm{ab}$ & $4,7 \mathrm{~d}$ \\
VC 3890B & $47,5 \mathrm{~b}$ & $74,0 \mathrm{a}-\mathrm{d}$ & $55,5 \mathrm{~b}$ & $67,7 \mathrm{a}$ & 1169 & $1,40 \mathrm{ab}$ & $6,4 \mathrm{abc}$ \\
VC 3902A & $47,7 \mathrm{~b}$ & $74,0 \mathrm{a}-\mathrm{d}$ & $60,4 \mathrm{~b}$ & $48,9 \mathrm{a}-\mathrm{d}$ & 1040 & $1,35 \mathrm{~b}$ & $7,7 \mathrm{ab}$ \\
VC 5734A & $46,7 \mathrm{~b}$ & $72,2 \mathrm{~cd}$ & $54,8 \mathrm{~b}$ & $61,8 \mathrm{ab}$ & 1209 & $1,75 \mathrm{a}$ & $7,6 \mathrm{ab}$ \\
\hline Média & 48,2 & 73,7 & 62,4 & 55,1 & 1093 & 1,53 & 6,4 \\
CV $(\%)$ & 2,9 & 1,5 & 4,3 & 14,5 & 15,7 & 9,6 & 10,7 \\
\hline
\end{tabular}

\footnotetext{
${ }^{1}$ Nas colunas, as médias seguidas da mesma letra não apresentam diferença significativa, a $5 \%$, pelo teste de Tukey. ns: não significativo a $5 \%$.

${ }^{2} 1$ - ótimo, 2 - bom, 3 - regular, 4 - ruim e 5 - péssimo. Avaliação realizada com as sementes provenientes da primeira colheita.
} 


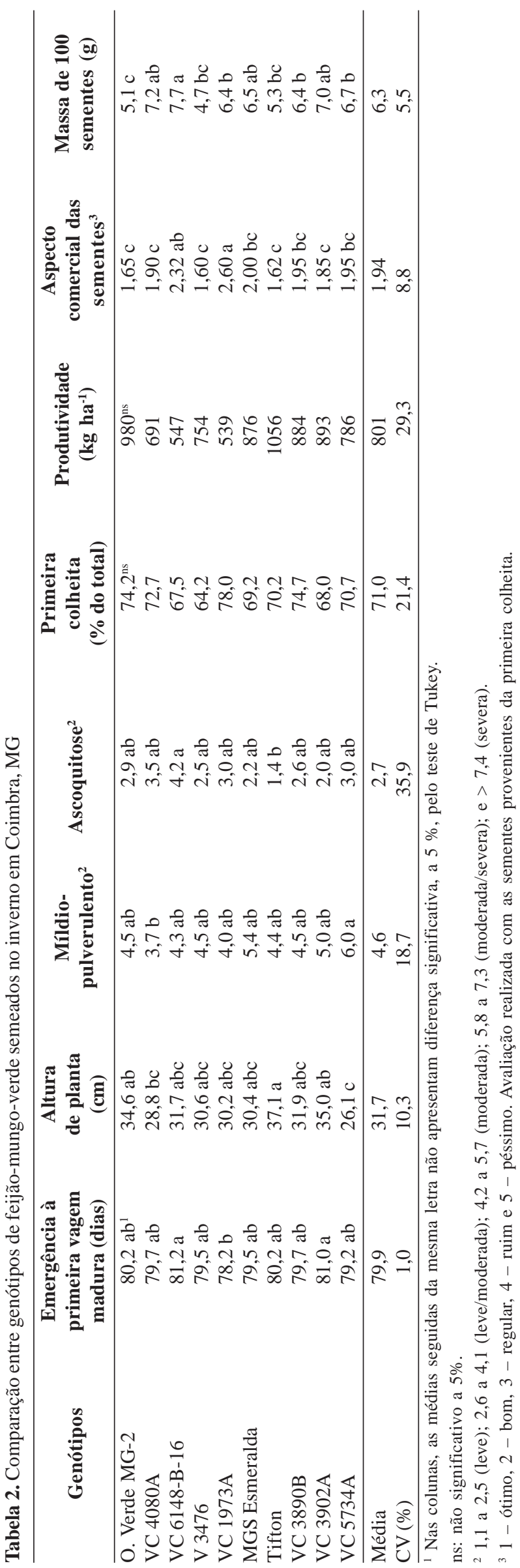

Tabela 3. Temperatura, precipitação e umidade relativa durante a condução dos ensaios em Oratórios e Coimbra, MG, 2002

\begin{tabular}{lccc}
\hline Mês & $\begin{array}{c}\text { Temp. média } \\
\left({ }^{\mathbf{0}} \mathbf{C}\right)\end{array}$ & $\begin{array}{c}\text { Precipitação } \\
(\mathbf{m m})\end{array}$ & $\begin{array}{c}\text { Umidade } \\
\text { relativa }(\boldsymbol{\%})\end{array}$ \\
\hline \multicolumn{4}{c}{ Oratórios } \\
agosto & 20,1 & 2,4 & 70 \\
setembro & 19,9 & 104,0 & 74 \\
outubro & 22,0 & 26 & 63 \\
\hline \multicolumn{4}{c}{ Coimbra $^{1}$} \\
\hline agosto & 19,4 & 0,1 & 70 \\
setembro & 19,0 & 77,2 & 75 \\
outubro & 22,0 & 29,5 & 68 \\
novembro & 21,9 & 218,2 & 79 \\
\hline
\end{tabular}

${ }^{1}$ Dados obtidos de estação climática localizada a $30 \mathrm{~km}$ do local do ensaio, numa altitude de $650 \mathrm{~m}$.

\section{CONCLUSÃO}

É possível produzir mungo-verde no inverno-primavera, mas seu potencial de rendimento é menor em relação aos meses mais quentes, especialmente a $720 \mathrm{~m}$, onde as condições climáticas favorecem algumas doenças.

\section{AGRADECIMENTOS}

À Fapemig, pelo financiamento do projeto que deu origem a este estudo. Ao CNPq, pelas bolsas concedidas aos pesquisadores: R. F. Vieira e T. J. de Paula Júnior.

\section{REFERÊNCIAS}

Duque FF \& Pessanha GG (1990) Comportamento de dez cultivares de mungo-verde nos períodos das águas e da seca em condições de campo. Pesquisa Agropecuária Brasileira, 25:963-969.

Van Shoonhoven A \& Pastor Corrales MA (1987) Standard system for evaluation of bean germoplasm. Cali, CIAT. 53p.

Vieira RF, Vieira C \& Vieira RF (2001) Leguminosas graníferas. Viçosa, Ed. UFV. 206p.

Vieira RF, Oliveira VR, Vieira C \& Pinto CMF (2002) 'Ouro Verde MG 2': nova cultivar de mungo-verde para Minas Gerais. Horticultura Brasileira, 20:119-120.

Vieira RF, Oliveira VR \& Vieira C (2003) Cultivo do feijão-mungoverde no verão em Viçosa e em Prudente de Morais. Horticultura Brasileira, 21:37-43.

Vieira RF, Pinto CMF \& Viana LF (2005) Comportamento de linhagens de mungo-verde no verão-outono na Zona da Mata de Minas Gerais. Revista Ceres, 52:153-164.

Vieira RF, Carneiro JES, Paula Júnior TJ de \& Araújo RF (2008) MGS Esmeralda: new large seed mungbean cultivar. Pesquisa Agropecuária Brasileira, 43:781-782. 